\title{
Soft Tissue Aneurysmal Bone Cyst: A Case Report
}

\author{
by Kevin M McCann, DPM ${ }^{1} \rrbracket$, Craig E Clifford, DPM ${ }^{2} \rrbracket$, Heather L Salton, DPM, AACFAS ${ }^{3} \otimes$
}

The Foot and Ankle Online Journal 4 (6): 1

The authors present an unusual case of a primary soft tissue tumor having histologic features identical to an intraosseous aneurismal bone cyst. A retrospective chart and radiographic review of a 44 year-old male was performed with a 17 month follow-up. Initially presenting as a painful, palpable nodule on the medial left ankle; a discreet, encapsulated mass was confirmed with ultrasound and magnetic resonance imaging. Surgical excision followed and pathologic analysis of the specimen diagnosed an aneurysmal bone cyst in soft tissue. Aneurysmal bone cysts usually appear in the metaphyses of long bones or in vertebral bodies. The primary soft tissue tumor is rare, with only 17 cases having been reported in the English literature. This is the first report of a primary soft tissue aneurysmal bone cyst in the distal lower extremity. In this case, as in the majority of reported cases, complete resolution was obtained with surgical excision.

Key words: Aneurysmal Bone Cyst, tumor of the foot, Magnetic Resonance Imaging.

Accepted: April, 2011

Published: June, 2011

This is an Open Access article distributed under the terms of the Creative Commons Attribution License. It permits unrestricted use, distribution, and reproduction in any medium, provided the original work is properly cited. OThe Foot and Ankle Online Journal (www.faoj.org), 2011 All rights reserved.

A neurysmal bone cyst $(\mathrm{ABC})$ is classically described as a benign lesion developing mostly in the metaphyses of long bones and in vertebral bodies. ${ }^{1}$ They are characterized by bloodfilled spaces separated by connective tissue septa containing fibroblasts, osteoclast-like giant cells, and reactive woven bone. ${ }^{2} \quad \mathrm{ABC}$ is considered a nonneoplastic lesion, although some cytogenetic studies have found reproducible chromosomal abnormalities. ${ }^{3,18}$ The majority of $\mathrm{ABCs}$ arise de novo (primary $\mathrm{ABC}$ ), but some have been found associated with other bony lesions secondarily. ${ }^{4,15}$

Address correspondence to: Kevin McCann, DPM. Franciscan Foot and Ankle Institute, $345099^{\text {th }}$ Ave S. Ste 306 Federal Way WA 98003

kevinmccann@,fhshealth.org

1,2 PGY 2. Franciscan Foot and Ankle Institute, $345099^{\text {th }}$ Ave S. Ste 306 Federal Way WA 98003.

${ }^{3}$ Attending Staff, Franciscan Foot and Ankle Institute, $345099^{\text {th }}$ Ave S. Ste 306 Federal Way WA 98003.
Lesions usually appear on radiograph as lytic and expansile. Computed tomography (CT) or magnetic resonance imaging (MRI) modalities often show a heterogeneous lesion with fluid-filled cystic spaces surrounded by a thin rim of bone. ${ }^{5} \quad$ Standard treatment of $\mathrm{ABCs}$ with marginal, yet complete surgical excision has shown acceptable results. ${ }^{3,5,6}$

While traditionally classified as a more common benign tumor of bone, ABCs have rarely been described as being found in soft tissues. A search of the English literature found a total of 17 cases of soft tissue $\mathrm{ABC}$, with no primary lesions previously described in the distal lower extremity. 3,4, 7-16 

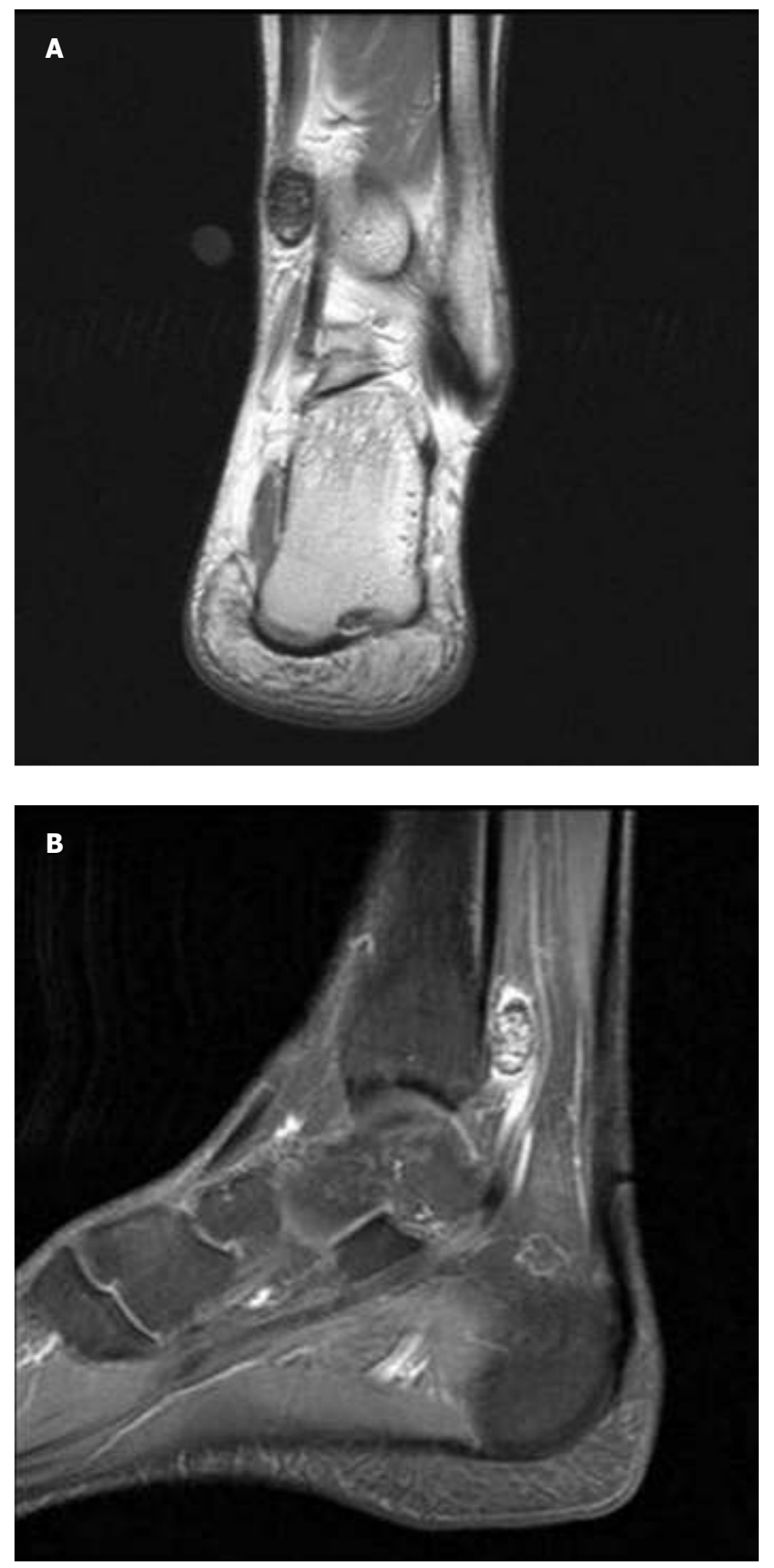

Figure 1A, 1B and 1C Magnetic resonance images (MRI) showing the heterogeneous, well-encapsulated mass immediately posterior to the flexor digitorum longus tendon. (A) Coronal Proton-dense T2. (B) Sagittal T1 image. (C) Axial T1 Image.

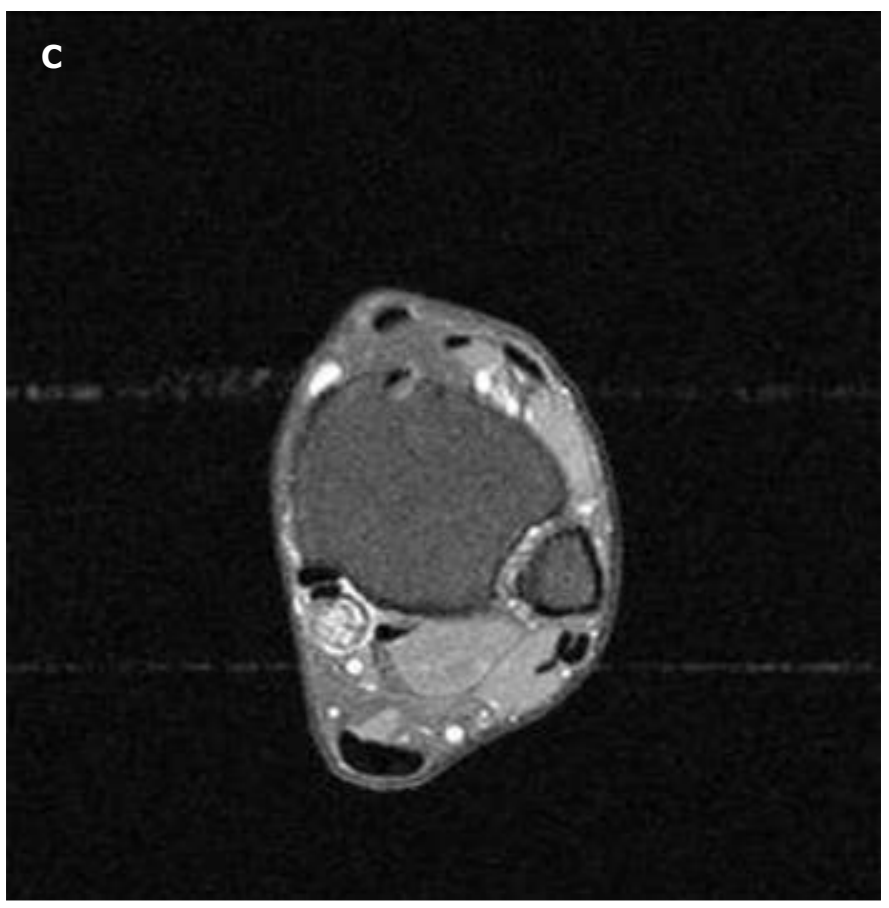

\section{Case Report}

The patient is a 44 year-old male who originally presented with complaints of a palpable "knot" in his medial left ankle, separate from and incidental to his chief complaint of hallux limitus on the contralateral limb. Initial exam showed a firm, semi-mobile, deep mass approximately $2 \mathrm{~cm}$ proximal and immediately posterior to the medial malleolus. This was mildly tender to palpation, but did not restrict motion of the lower extremity. Ultrasound exam revealed a $5 \mathrm{x}$ $10 \mathrm{~mm}$ mass posterior to the tibialis posterior tendon. The mass was heterogeneous and ill-defined, without evidence of attachment to adjacent structures.

After one month of observation, the patient expressed continued pain and possible increasing size. An MRI exam was performed to show a $1.8 \times 1 \mathrm{~cm}$ heterogeneous mass abutting the flexor digitorum longus tendon. (Figs. 1A, 1B and 1C) A decision was made to perform a complete excisional biopsy.

Surgical dissection revealed a firm, purplish-brown, well-encapsulated mass within membranous soft tissue and with no defined attachment to surrounding structures. (Fig. 2A) 


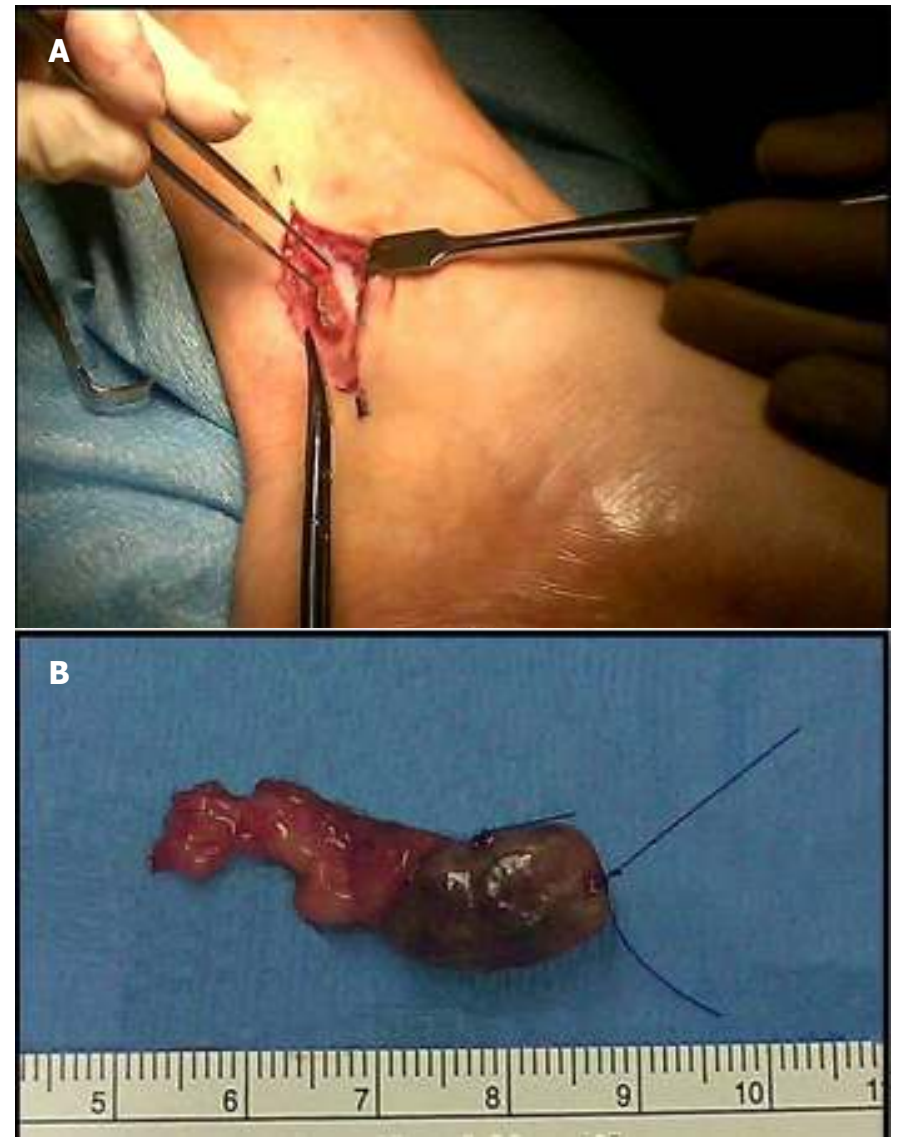

Figure 2A and 2B Intra-operative (A) and gross specimen photos (B) showing the excised mass with attached membranous soft tissue, and its location posterior to the tibialis posterior tendon.

The mass was tagged with suture to identify orientation and submitted to pathology as a single specimen. (Fig. 2B) The patient healed uneventfully with full weight-bearing in the immediate postoperative phase.

The specimen margins were inked per orientation and the mass was sectioned to reveal a "variegated red-yellow cut surface with calcified tissue and extensive hemorrbage." Microscopic analysis proved inconclusive and slides were sent to an outside pathology lab for independent review by multiple pathologists. The final pathology report is as follows: "The specimen is a circumscribed nodular heterogeneous lesion."

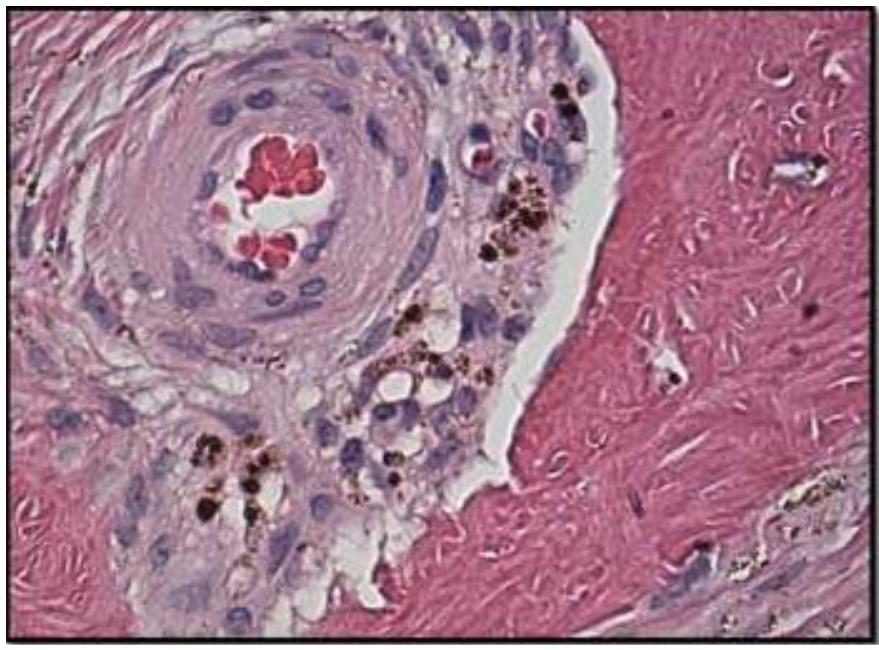

Figure 3 Prepared H\&E stained slide showing histologic features of aneurysmal bone cyst in soft tissue at $40 \mathrm{X}$ magnification.

Hemosiderotic synovium and a pool of muscularwalled, variably sized vessels are seen at the periphery of the nodule. The nodule had a vaguely multilobulated configuration with blood-filled pseudocystic spaces alternating with spindle cell areas and areas of bone formation. The center of the lesion is occupied by well-formed bone with spicules that radiate outward. The outer rim of the nodule demonstrates a discontinuous thin shell of bone. Numerous giant cells are seen within the blood filled spaces. Prominent hemosiderin deposition is seen within the intervening spindle-cell areas. The histologic features are those of so-called aneurismal bone cyst of soft tissue. (Fig. 3) No neoplasm is seen. The patient remains without symptoms or signs of recurrence at a follow-up of 17 months postoperatively.

\section{Discussion}

Unlike the more common primary bone lesion, soft tissue aneurysmal bone cyst is a rarely occurring pathology. A search of English language databases revealed a total of 17 cases of soft tissue $A B C$ as reported by 12 authors. ${ }^{3,4,7-16}$ 


\begin{tabular}{|c|c|c|c|c|c|c|}
\hline Case & Published & Author & Age & Sex & Location & Size $(\mathrm{cm})$ \\
\hline 1 & 1972 & Salm and Sissons & 32 & $\mathbf{M}$ & Thigh & 6 \\
\hline 2 & 1972 & Salm and Sissons & 45 & $\mathbf{F}$ & Abdominal wall & 3.5 \\
\hline 3 & 1992 & Amir et al. & 15 & $\mathbf{F}$ & Groin & 2 \\
\hline 4 & 1993 & Petriketal. & 7 & $\mathbf{M}$ & Common carotid A. & 3 \\
\hline 5 & 1994 & Rodriguez-Perralto et al. & 20 & $\mathbf{F}$ & Shoulder & 6 \\
\hline 6 & 1996 & Lopez-Barea et al. & 57 & $\mathbf{F}$ & Upper arm & 7 \\
\hline 7 & 1997 & Shannonet al. & 29 & $\mathbf{F}$ & Retroclavicular tissues & 4.5 \\
\hline 8 & 2002 & Nielson et al. & 8 & $\mathbf{M}$ & Shoulder & 8 \\
\hline 9 & 2002 & Nielson et al. & 29 & $\mathbf{F}$ & Groin & 4 \\
\hline 10 & 2002 & Nielson et al. & 37 & $\mathbf{F}$ & Upper arm & 2.5 \\
\hline 11 & 2002 & Nielson et al. & 28 & $\mathbf{M}$ & Shoulder & 9 \\
\hline 12 & 2002 & Nielson et al. & 30 & $\mathbf{F}$ & Thigh & 4 \\
\hline 13 & 2005 & Ajilogha et al. & 12 & $\mathbf{F}$ & Thigh & 4 \\
\hline 14 & 2007 & D'Costa et al. & 60 & $\mathbf{F}$ & Breast & 10 \\
\hline 15 & 2007 & Karkuzhali et al. & 23 & $\mathbf{M}$ & Proximal fibula & 3 \\
\hline 16 & 2008 & Sahuet al. & 12 & $\mathbf{F}$ & Palmar side thenar hand & 4.5 \\
\hline 17 & 2009 & Fellig et al. & 25 & $\mathbf{M}$ & Cerebello-pontine angle & 3.3 \\
\hline 18 & 2011 & McCann et al. & 44 & $\mathbf{M}$ & Distal lower extremity & 1.8 \\
\hline
\end{tabular}

Table 1 Summary of reported cases of soft tissue aneurysmal bone cyst (ABC).

Salm and Sissons ${ }^{7}$ first described two cases of extraosseus giant-cell tumors having histologic features identical to bony ABC in 1972. Since then, 16 cases (including this report) have been reported occurring in various locations, and are summarized in Table 1. Patients are made up of eleven females and six males ranging in age from $7-60$ years with a median age of 28. Tumors showed histologic features identical to the bony $A B C$ and ranged in size from $1.8 \mathrm{~cm}$ to $10 \mathrm{~cm}$ with a median of $4 \mathrm{~cm}$. Lesions were most often located in the deep soft tissues of the upper extremity or shoulder ${ }^{7}$, or thigh. ${ }^{3}$ All cases described were treated by surgical excision. Recurrence rate is unknown due to the small number of cases and inadequate follow-up.
Recently, Karkuzhali et al., ${ }^{15}$ described a case of multiple soft tissue ABC's arising following excision of a bony $\mathrm{ABC}$ from the proximal fibula 20 months prior, possibly suggesting a neoplastic course. Cytogenetic studies ${ }^{3,18}$ have shown an association with translocations at the $16 \mathrm{q} 22$ and $17 \mathrm{p} 13$ loci, providing further evidence of a possible neoplastic etiology. It has been proposed that the lesion is first formed as a reaction to ectopic bone, but is more likely the result of a primary arteriovenous malformation. ${ }^{3}$

Despite the usual appearance of aneurysmal bone cyst in long bone metaphyses, the foot and ankle surgeon should be aware that it may also manifest as a soft tissue lesion of the lower extremity. 


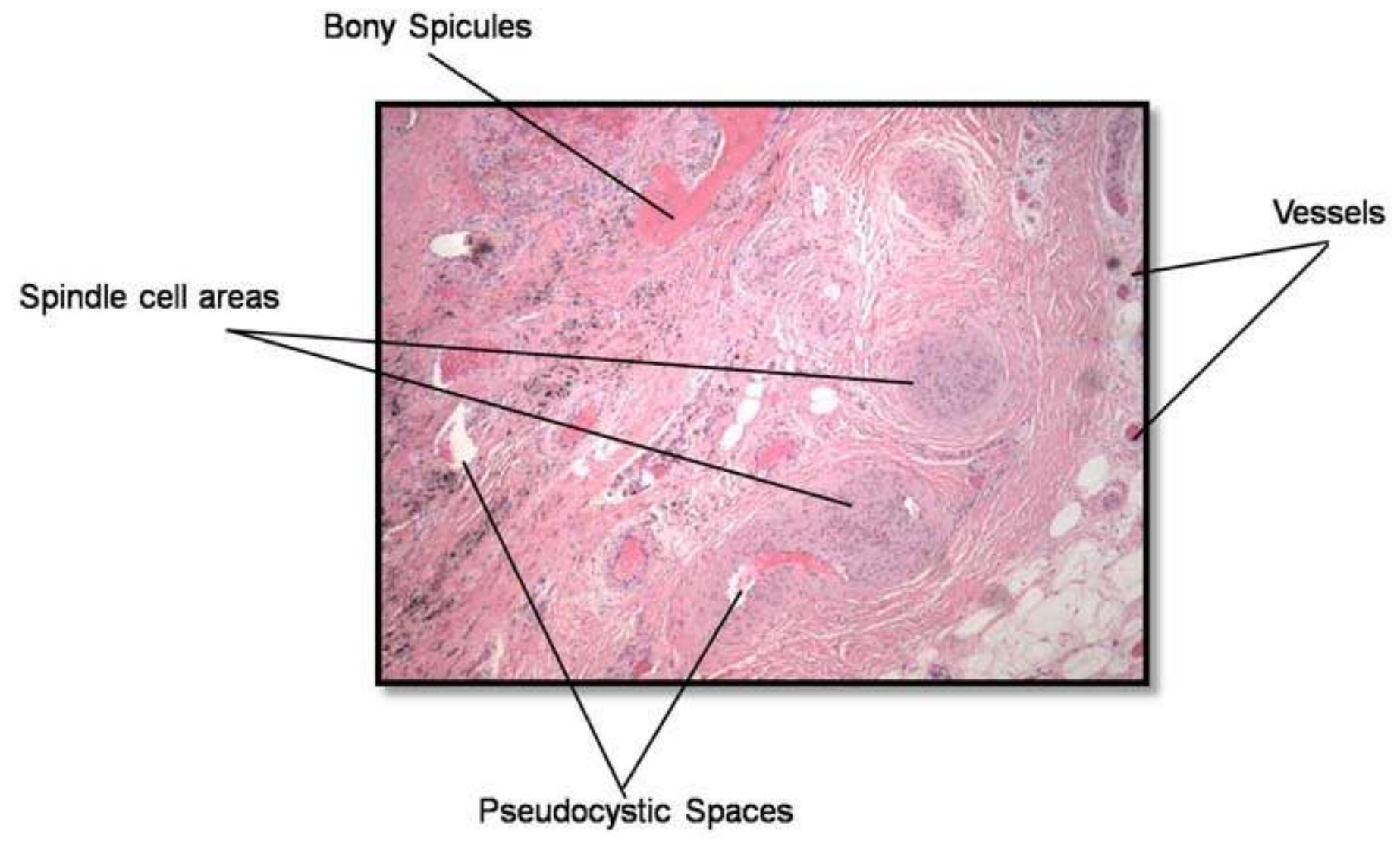

Figure 4 Pathologic identification of soft tissue $A B C$.

The differential diagnosis of soft tissue $A B C$ can include nodular fasciitis and ossifying fibromyxoid tumor. Nodular fasciitis lesions may histologically mimic soft tissue $\mathrm{ABC}$, but do not contain the characteristic pseudocystic spaces or thin shell of bone. Ossifying fibromyxoid tumors often show spicules of bone, but are without osteoclastic-like giant cells characteristic of soft tissue $\mathrm{ABC}^{3}$ Definitive diagnosis is made based on microscopic pathology, which is undistinguishable from the classic bony lesion. (Fig. 4)

The exact etiology of soft tissue ABC's remains unknown. While the lesion can be aggressive in growth, it is benign and can be successfully treated with surgical excision.

\section{References}

1. Vergel De Dios AM, Bond JR, Shives TC, McLeod RA, Unni KK. Aneurysmal bone cyst. A clinicopathologic study of 238 cases. Cancer 1992 69: 2921-2931.

2. Leithner A, Machacek F, Haas OA, Lang S, Ritschl P, Radl R, Windhager R. Aneurysmal bone cyst: a hereditary disease? J Pediatr Orthop B 2004 13: 214-217.

3. Nielsen GP, Fletcher CD, Smith MA, Rybak L, Rosenberg AE. Soft tissue aneurysmal bone cyst: a clinicopathologic study of five cases. Am J Surg Pathol 2002 26: 64-69.

4. Fellig Y, Oliveira AM, Margolin E, Gomori JM, EricksonJohnson MR, Chou MM, Umansky F, Soffer D. Extraosseous aneurysmal bone cyst of cerebello-pontine angle with USP6 rearrangement. Acta Neuropathol 2009 118: 579-581.

5. Abuhassan FO, Shannak AO. Subperiosteal resection of aneurysmal bone cysts of the distal fibula. JBJS 2009 91B:12271231.

6. Chowdhry M, Chandrasekar CR, Mohammed R, Grimer RJ. Curettage of aneurysmal bone cysts of the feet. Foot Ankle Int 2010 31: 131-135. 
7. Salm R, Sissons HA. Giant-cell tumors of soft tissues. J Pathology 1972 107: 27-39.

8. Amir G, Mogle P, Sucher E. Case report 729: myositis ossificans and aneurysmal bone cyst. Skeletal Radiology 1992 21: 257-259.

9. Petrik PK, FindlayJM, Sherlock RA. Aneurysmal cyst, bone type, primary in an artery. Am J Surg Pathol 1993 17: 1062-1066. 10. Rodriguez-Perralto JL, Lopez-Barea F, Sanchez-Herrera S, Atienza M. Primary aneurysmal cyst of soft tissues (extraosseus aneurysmal cyst). Am J Surg Pathol 1994 18:632-636.

11. Lopez-Barea F, Rodriguez-Perralto JL, Burgos-Lizaldez E, Alvarez-Linera J, Sánchez-Herrera S. Primary aneurysmal cyst of soft tissue: report of a case with ultrastructural and MRI studies. Virchows Arch 1996 428: 125-129.

12. Shannon P, Bedard Y, Bell R, Kandel R. Aneurysmal cyst of soft tissue: report of a case with serial MRI and biopsy. Human Pathol 1997 28: 255-257.

13. Ajilogha KA, Kaur H, Duncan R, McFarlane JH, Watt AJ. Extraosseous aneurismal bone cyst in a 12 year-old girl. Pediatr Radiol 2005(12):1240-2.

14. D'Costa GF, Hastak MS, Patil YV. Primary aneurysmal cyst: bone type in the breast. Ind J Surg 2007 69: 248-250. 15. Karkuzhali P, Bhattacharyya M, Sumitha P. Multiple soft tissue aneurysmal cysts: An occurrence after resection of primary aneurysmal bone cyst of fibula. Ind J Orthop 2007 41:246-249. 16. Sahu A, Gujral SS, Gaur S. Extraosseous aneurysmal cyst in hand: a case report. Cases J 2008 1: 268.

17. Harrop JS, Schmidt MH, Boriani S, Shaffrey CI. Aggressive "benign" primary spine neoplasms: osteoblastoma, aneurysmal bone cyst, and giant cell tumor. Spine 200934 (22 Suppl): S3947.

18. Dai cin P, Kozakewich HP, Goumnerova L, Mankin HJ, Rosenberg AE, Fletcher JA. Variant translocations involving 16 q22 and 17p13 in solid variant and extra osseous forms of aneurysmal bone cyst. Gen Chrom Cancer 2000 (28): 233-234. 